\title{
Patients' Attitude and Knowledge About Epilepsy in the North of Iran in 2016 - 2018
}

\author{
Narges Karimi ${ }^{1,{ }^{*}}$, Ashraf Zarvani ${ }^{2}$ and Seyyed Ali Akbarian ${ }^{3}$ \\ ${ }^{1}$ Department of Neurology, Immunogenetics Research Center, School of Medicine, Clinical Research Development Unit of Bou Ali Sina Hospital, Mazandaran University of \\ Medical Sciences, Sari, Iran \\ ${ }^{2}$ Department of Neurology, School of Medicine, Mazandaran University of Medical Sciences, Sari, Iran \\ ${ }^{3}$ Department of Emergency Medicine, School of Medicine, Mazandaran University of Medical Sciences, Sari, Iran \\ "Corresponding author: Department of Neurology, Clinical Research Development Unit of Bou Ali Sina Hospital, Mazandaran University of Medical Sciences, Sari, Iran. Tel: \\ +98-1133343018, Fax: +98-1133344506, Email: drkarimi_236@yahoo.com
}

Received 2018 December 24; Revised 2020 February 03; Accepted 2020 July 11.

\begin{abstract}
Background: Epilepsy is a severe problem incorporating a high degree of the misconception that influences the quality of life of individuals suffering from the disease.

Objectives: The purpose of the present study was to assess the knowledge and attitudes of patients with epilepsy toward the disease. Methods: A cross-sectional study was conducted on 155 individuals with epilepsy aged $\geq 18$ years from August 2016 to Jun 2018 in an outpatient clinic of a medical university in Sari City, North of Iran. Thirty-four closed-ended questions were developed, including 14 items about knowledge, 11 items about attitudes, and nine questions about knowledge profile-personal toward epilepsy. Answers to the questions were either "yes," "no," or "I do not know." The chi-square $\left(\chi^{2}\right)$ test was used to explain the association between variables and demographic information.

Results: The mean age of the participants was $31.73 \pm 11.06$ years. Regarding the cause of epilepsy, $85.8 \%$ of the participants reported that epilepsy is a brain disorder. Moreover, in terms of the knowledge score, $54.8 \%$ of the participants had a fair knowledge of epilepsy. Accordingly, patients with university education had good knowledge about the disease $(\mathrm{P}=0.007)$. In terms of attitudes toward epilepsy, $82.6 \%$ of the patients had a positive attitude toward the disease but had no good awareness of it. These positive attitudes were associated with a high education level $(\mathrm{P}=0.001)$.

Conclusions: This study showed that despite the positive attitude toward epilepsy, good knowledge about the disease was still below $50 \%$.
\end{abstract}

Keywords: Attitude, Epilepsy, Knowledge, Iran, Patient

\section{Background}

Epilepsy is the most common chronic illness of the brain that affects people of all ages, genders, and races. It is estimated that more than 70 million people globally have epilepsy, and $80 \%$ of them live in developing countries ( 1 , $2)$. The point prevalence of active epilepsy has been estimated at 6.38 per 1,000 persons (3). A systematic review and meta-analysis conducted in Iran showed the prevalence of epilepsy to be around 5\% (4). Epilepsy brings about severe problems with an extraordinary amount of social stigma, having a destructive effect on the quality of life (QOL) of people with epilepsy (PWE), especially in developing countries (5-8). These patients experience several social, psychological, and economic problems associated with poor QOL $(9,10)$.

The lack of knowledge about epilepsy is associated with negative attitudes and beliefs, as well as a prominent stigma at the workplace and school (1-11). Many people with epilepsy endure intense degrees of depression, anxiety, and fatigue, and are susceptible to social and occupational restrictions that usually are conveyed with the disease diagnosis $(12,13)$. Several factors can affect the QOL of these patients. These factors include social determinants, family situations, seizure occurrence, and proportion of response to treatment $(14,15)$. In a previous study carried out in Iran, unemployment and low education were expressively associated with a high level of stigma development (16). Good knowledge about epilepsy is connected with a lower extent of stigmatization and social separation, as well as a lower level of depression and misconception (17). Beside improved self-effectiveness and social care, a positive attitude toward the disease is effective in ameliorating self-handling $(18,19)$. Hence, it is relevant to 
determine the attitudes and knowledge of patients with epilepsy. Although several studies have been performed in Iran on the knowledge and attitudes about epilepsy, they have mostly focused on specific community groups such as relatives, teachers, general populations, and other groups $(15,20-22)$.

\section{Objectives}

The attitudes and knowledge of PWE toward their disease have been inadequately investigated. Thus, the goal of the present study was to assess the knowledge and attitudes of patients with epilepsy toward their disease.

\section{Methods}

This study was permitted by the Ethics Committee of Mazandaran University of Medical Sciences.

\subsection{Study Design and Location}

A cross-sectional study was conducted from August 2016 to Jun 2018 in an outpatient clinic of a medical university (Tooba Clinic) in Sari city, the North of Iran. The clinic is a tertiary referral center for all urban and rural regions of Mazandaran Province, Iran, and a teaching clinic affiliated to the Mazandaran University of Medical Sciences.

\subsection{Inclusion and Exclusion Criteria}

The study sample included adult ( $\geq 18$ years of age) patients with epilepsy for more than six months attending a neurology outpatient clinic for usual follow-ups. Patients who had single seizures were illiterate or had dementia, or other forms of non-epileptic neurological or psychological deficiency were excluded. With a confidence level of $95 \%$ and an error rate of 5\%, a total of 155 PWE participated in this study.

\subsection{Study Questionnaire and Measures}

The questionnaire consisted of demographic data and closed-ended questions. Thirty-four questions were established after a widespread review of the literature (23-25). The questions were translated from English into Farsi and then back-translated by neurologists. Straightforwardness, truthfulness, and implication were attentively investigated. A pilot study was conducted on 25 randomly selected PWE with an interval of two weeks to corroborate the reliability and consistency of the Farsi version of the questionnaire. The reliability of the questionnaire was confirmed by Cronbach's alpha, which gave rise to the internal consistency of 0.75 . The sociodemographic characteristics consisted of age, sex, marital status, education, occupation, and the number of family members. The closedended questions included 14 questions about knowledge, 11 questions about attitudes, and nine questions about epilepsy knowledge profile-personal. The responses to the questions were either "yes," "no," or "I do not know." The participants completed the questionnaires at an established time and place. The investigators would help the participants if there were any questions. The knowledge, attitude, and knowledge profile-personal of the patients were assessed individually for each participant. Each correct answer was given one point, while the wrong or "I do not know" responses scored zero. For the assessment of the total attitude and knowledge of the contributors, the scores were summed up for each participant. The score range was 0 - 14 for knowledge, 0 - 11 for attitudes, and 0 - 9 for epilepsy knowledge profile-personal. The level of knowledge and attitude was categorized based on the score or percentage of correct answers. Hence, the knowledge of patients was categorized as poor ( $0-7$ or $\leq 50 \%$ ), fair ( $8-10$ or $51 \%-75 \%$ ), and good (11- 14 or $>75 \%$ ). The attitude score was categorized as either negative $(0-6$ or $\leq$ $50 \%$ ) or positive ( $7-11$ or $>51 \%)$. Further, the knowledge profile-personal score was considered either poor ( 0 - 5 or $\leq 50 \%)$ or $\operatorname{good}(6-9$ or $>51 \%)(15,23)$.

\subsection{Statistical Analysis}

The data were analyzed using SPSS version 22.0 (SPSS Inc., Chicago, IL, USA). The demographic information and epilepsy knowledge and attitudes were presented using descriptive statistics (mean, percentage, and frequency distribution). The chi-square $\left(\chi^{2}\right)$ was used to determine the association between variables and demographic data. The results were considered significant at $\mathrm{P}<0.05$.

\section{Results}

The mean age of the participants was $31.73 \pm 11.06$ years (range: 16 - 65); 60\% were female (mean age $=32.38 \pm 10.95$ ), and $40 \%$ were male (mean age $=30.75 \pm 11.25$ ). There was no significant difference in the age range between the genders. The majority of the participants (99 out of $155 ; 63.9 \%$ ) were married. Concerning the education level, $69 \%$ of the participants had a diploma degree or college education. The demographic data are shown in Table 1. 


\begin{tabular}{|c|c|}
\hline Variables & Values \\
\hline \multicolumn{2}{|l|}{ Gender } \\
\hline Male & $62(40.0)$ \\
\hline Female & $93(60.0)$ \\
\hline \multicolumn{2}{|l|}{ Age, $y$} \\
\hline $18-28$ & $59(38.1)$ \\
\hline $29-39$ & $41(26.5)$ \\
\hline $40-50$ & $41(26.5)$ \\
\hline$>50$ & $14(9.0)$ \\
\hline \multicolumn{2}{|l|}{ Marital status } \\
\hline Single & $5(35.5)$ \\
\hline Married & $99(63.9)$ \\
\hline Widowed or divorced & $1(0.60)$ \\
\hline \multicolumn{2}{|l|}{ Education level } \\
\hline Primary school & $18(11.6)$ \\
\hline Secondary school & $30(19.4)$ \\
\hline Diploma & $67(43.2)$ \\
\hline University education & $40(25.8)$ \\
\hline \multicolumn{2}{|l|}{ Occupation } \\
\hline Unemployed & $32(20.6)$ \\
\hline Employed & $18(11.6)$ \\
\hline Housewife & $64(41.3)$ \\
\hline Professional & $41(36.5)$ \\
\hline \multicolumn{2}{|c|}{ Number of members in the family } \\
\hline$<3$ & $45(29.0)$ \\
\hline $3-5$ & $90(58.1)$ \\
\hline$>5$ & $20(12.9)$ \\
\hline
\end{tabular}

${ }^{\mathrm{a}}$ Values are expressed as No. (\%).

\subsection{Knowledge About Epilepsy}

Regarding the cause of epilepsy, $85.8 \%$ of the participants reported that epilepsy is a brain disorder, while only $6.5 \%$ of the participants described that epilepsy is caused by demon possession or supernatural powers. In addition, in terms of factors provoking a seizure attack, 61.3\%, 70.3\%, and $53.5 \%$ of the patients mentioned that starvation, insomnia, and watching TV or working with a computer for the long run could cause seizures, respectively. The subjects' knowledge about epilepsy is demonstrated in Table 2. In terms of the knowledge score, 12 (7.7\%), 85 (54.8\%), and 58 (37.4\%) of the participants had poor, fair, and good knowledge about epilepsy, respectively. There was a significant relationship between the education level and knowledge about epilepsy. Accordingly, patients with univer- sity education had good knowledge about the disease ( $\mathrm{P}$ $=0.007$ ). However, there was no significant relationship between other demographic information and knowledge about epilepsy.

\subsection{Attitude Toward Epilepsy}

The majority of the respondents agreed that PWE could marry. Moreover, most of the patients had positive attitudes toward having appropriate occupations and college education. Nevertheless, more than half of the patients reported that PWE could drive and swim safely. Table 3 demonstrates the patients' attitudes toward epilepsy. In general, $17.4 \%$ and $82.6 \%$ of the patients had negative and positive attitudes toward the disease based on the attitude score, respectively. Additionally, $89.7 \%$ of the responders mentioned that PWE could marry, $65.2 \%$ of whom had a diploma degree or higher education $(P=0.001)$. A significant relationship was observed between the education level and marital status (0.02). Moreover, 83.9\% of the patients declared that PWE could find an appropriate occupation, and 91\% of the participants stated that PWE could have a university education. These positive attitudes were associated with a high education level $(\mathrm{P}=0.001)$.

\subsection{Patient Knowledge Profile-Personal}

In terms of patients' self-assessment about their epilepsy, $60 \%$ of the patients recognized truthful names for their seizure types. In addition, $55.5 \%$ and $43.2 \%$ of the patients were aware of the results of their electroencephalograms and brain imaging, respectively. The majority of the patients (92.9\%) were consuming antiepileptic medications according to the physicians' instructions. However, most of the patients were unaware of the side effects of the medications during pregnancy and on the fetus. Table 4 shows the percentage of respondents based on the answer "yes" and "no". In general, 50.3\% of the patients had poor knowledge and $49.7 \%$ of them had good knowledge based on the patients' knowledge profilepersonal scores. In this study, a significant correlation was found between gender and knowledge profile-personal ( $P$ $=0.009$ ).

\section{Discussion}

Overall, in our study, the patients' knowledge about epilepsy was fair to good among people suffering from this disease. A vast majority of the participants were familiar with the causes of epilepsy. Moreover, the majority of the participants mentioned that the prominent cause of epilepsy was a brain disorder, while a few of them believed that epilepsy was contagious or caused by supernatural powers. These findings are similar to those of previous 


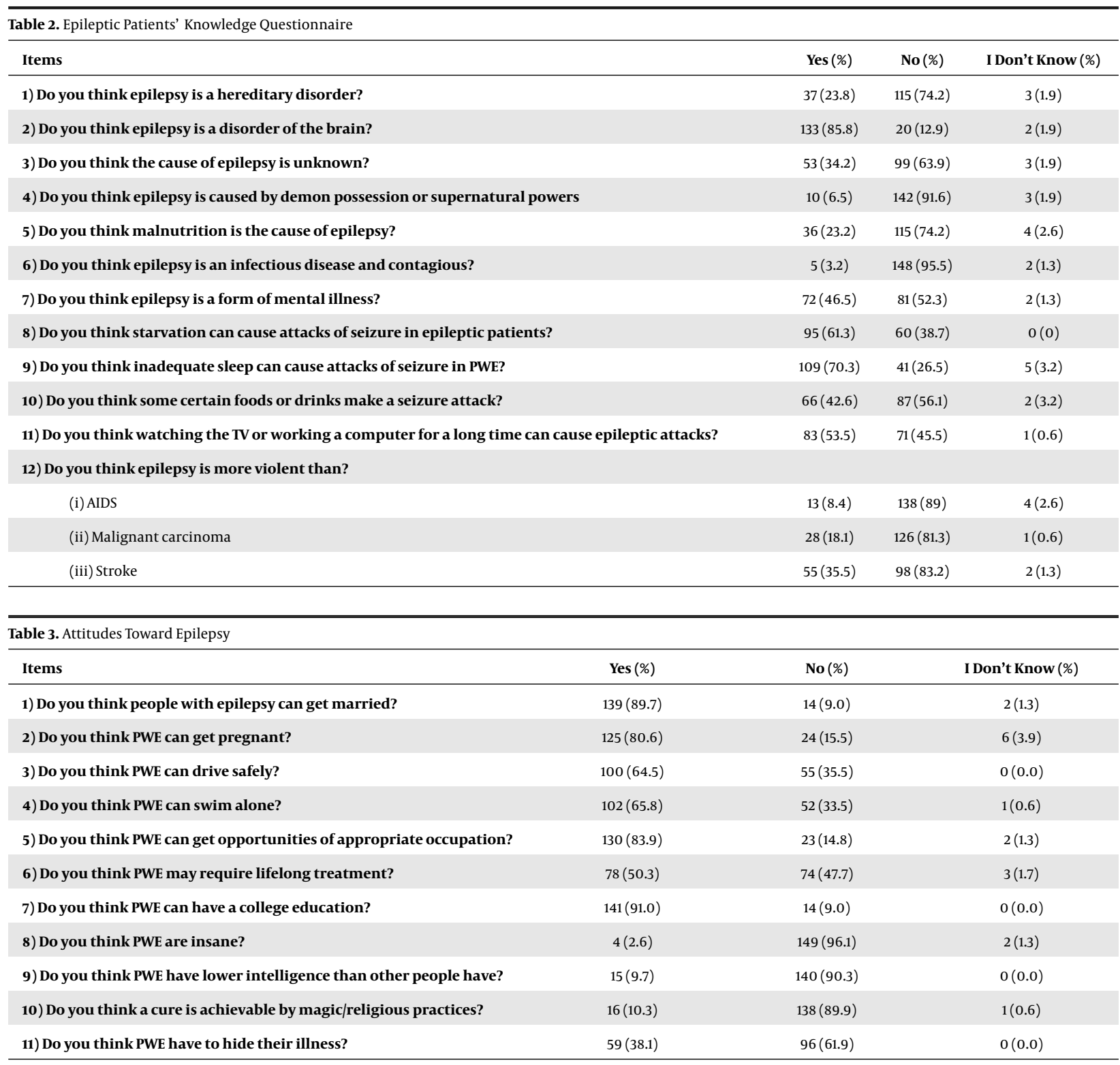

Abbreviation: PWE, people with epilepsy.

studies in Iran $(15,19,21)$. Previous studies in Iran have been mostly conducted on specific community groups such as teachers, the general public, and first-degree relatives (15, 19, 21). Ghanean et al. (22) reported that public knowledge was good about epilepsy.

Moreover, a vast majority of the studies regarded a brain disease as the cause of epilepsy, and none blamed evil spirits (21). These results are different from those of other studies conducted in developing countries such as southwestern Nigeria, India, and China where the majority of the participants recognized epilepsy as a supernatural or mental illness (26-28). On the other hand, in the present study, nearly half of the participants believed that epilepsy was a mental illness, and one-fourth of the participants considered epilepsy as a malnutrition disorder. This misconception was also reported in previous studies in different countries (29-32). Differences observed in studies may be correlated with cultural variations or educational levels of the population surveyed.

In this study, proper awareness of epilepsy was associated with a high level of literacy. Accordingly, patients with higher education had higher epilepsy knowledge scores 


\begin{tabular}{|c|c|c|}
\hline Items & Yes (\%) & No(\%) \\
\hline 1) Do you know your seizure type? & $93(60.0)$ & $62(40.0)$ \\
\hline $\begin{array}{l}\text { 2) Do you know the results of your EEG } \\
\text { assessment? }\end{array}$ & $86(55.5)$ & $69(45.5)$ \\
\hline $\begin{array}{l}\text { 3) Do you know the results of your brain } \\
\text { imaging? }\end{array}$ & $67(43.2)$ & $88(56.8)$ \\
\hline $\begin{array}{l}\text { 4) Do you take antiepileptic drugs regularly } \\
\text { according to the physician's prescription? }\end{array}$ & $144(92.9)$ & $11(7.1)$ \\
\hline $\begin{array}{l}\text { 5) Do you know the side effects of antiepileptic } \\
\text { drugs? }\end{array}$ & $67(43.2)$ & $88(56.8)$ \\
\hline $\begin{array}{l}\text { 6) Do you know the side effects of antiepileptic } \\
\text { drugs on the fetus? }\end{array}$ & $45(29.0)$ & $110(71.0)$ \\
\hline $\begin{array}{l}\text { 7) Do patients with epilepsy have to use } \\
\text { antiepileptic drugs only at the time of seizure } \\
\text { attack? }\end{array}$ & $25(16.1)$ & $130(83.9)$ \\
\hline $\begin{array}{l}\text { 8) Have you ever acknowledged information } \\
\text { about epilepsy? }\end{array}$ & $115(74.2)$ & $40(25.8)$ \\
\hline \multicolumn{3}{|l|}{ 9) If yes, what resources did you have? } \\
\hline Physician & $(55.5)$ & \\
\hline Mass media & $(7.7)$ & \\
\hline Book & (11) & \\
\hline
\end{tabular}

than those with lower education, as previously reported in other studies $(33,34)$. In addition, in the present study, more than half of the participants reported that inadequate sleep, watching TV, working with a computer for a long time, and starvation could increase the risk of seizure attacks, similar to the outcomes from other studies $(15,18$, 29). However, studies are limited concerning the effect of starvation on seizure attacks. In response to questions on comparing epilepsy with other disorders, the majority of the participants believed that stroke, malignancy, and AIDS were more violent than epilepsy. Such beliefs are highly important in the psychosocial aspect because they help PWE to better control and manage their seizures. Further, the majority of the responders had positive attitudes toward epilepsy. They believed that PWE did not have lower intelligence than other people and could find appropriate occupations. The current study also revealed that PWE with a lower education level often had negative attitudes about epilepsy. Nevertheless, there were misconceptions about the driving and swimming capabilities of PWE. In Iran, patients with epilepsy cannot legally obtain a driving license, and this misconception may be harmful to patients. Moreover, patients are constantly warned about swimming without supervision. In our study, $61.1 \%$ of the responders mentioned that they hide their disease from others, which is a finding similar to other study results (17, 35). Aydemir et al. (35) reported that the reason for hiding epilepsy could be the fear of others' attitudes and also the fear of discrimination. In the present study, more than half of the patients knew their seizure type correctly and were aware of their electroencephalography results. These results are similar to those of Coker et al.'s study (25). Most of the patients consumed antiepileptic drugs regularly but were not aware of their side effects. Overall, PWE had poor knowledge about their disease, which is similar to the results of Mameniskiene et al.'s study (33). In this regard, males had less knowledge about the disease than females. This finding is similar to those of Jacoby et al. and Spott et al.'s studies $(36,37)$. However, for more detailed analyses, larger sample sizes are required.

\subsection{Conclusions}

This study showed that despite the positive attitude toward epilepsy, good knowledge about the disease is still below $50 \%$. Given that the majority of the patients were consuming antiepileptic medications according to the physician's instructions, most of them were unaware of the side effects of the medications. Limited knowledge about epilepsy among PWE appears to be a feature related to their illness and can depend on the education level and culture. These results indicate that there is still a need for educational programs to raise epileptic patients' awareness of their disease. Education to people with epilepsy and their families causes them to know misconceptions, promote the quality of life, and reduce concerns about stigma. This training should be provided by the health care system, especially epilepsy centers.

\section{Footnotes}

Authors' Contribution: Narges Karimi, Ashraf Zarvani and Seyyed Ali Akbarian studied and designed the concept. Narges Karimi analyzed and interpreted the data. Narges Karimi, Ashraf Zarvani, and Seyyed Ali Akbarian drafted the manuscript. Narges Karimi and Ashraf zarvani revised the manuscript for important intellectual content. Narges Karimi analyzed the data.

Conflict of Interests: None of the authors have any conflict of interest to disclose.

Ethical Approval: This study was permitted by the Ethics Committee of Mazandaran University of Medical Sciences.

Funding/Support: None.

\section{References}

1. WHO. Epilepsy. Geneva: World Health Organization; 2009.

2. Ngugi AK, Bottomley C, Kleinschmidt I, Sander JW, Newton CR. Estimation of the burden of active and life-time epilepsy: A meta-analytic approach. Epilepsia. 2010;51(5):883-90. doi: 10.1111/j.1528-1167.2009.02481.x. [PubMed: 20067507]. [PubMed Central: PMC3410521]. 
3. Fiest KM, Sauro KM, Wiebe S, Patten SB, Kwon CS, Dykeman J, et al. Prevalence and incidence of epilepsy: A systematic review and meta-analysis of international studies. Neurology. 2017;88(3):296303. doi: 10.1212/WNL.0000000000003509. [PubMed: 27986877]. [PubMed Central: PMC5272794].

4. Sayehmiri K, Tavan H, Sayehmiri F, Mohammadi I, V. Carson K. Prevalence of epilepsy in Iran: A meta-analysis and systematic review. Iran J Child Neurol. 2014;8(4):9-17. [PubMed: 25657765]. [PubMed Central: PMC4307363].

5. Covanis A, Guekht A, Li S, Secco M, Shakir R, Perucca E. From global campaign to global commitment: The World Health Assembly's Resolution on epilepsy. Epilepsia. 2015;56(11):1651-7. doi: 10.1111/epi.13192. [PubMed: 26391429].

6. Jacoby A. Epilepsy and the quality of everyday life. Soc Sci Med. 1992;34(6):657-66. doi: 10.1016/0277-9536(92)90193-t.

7. Kobau R, Price P. Knowledge of epilepsy and familiarity with this disorder in the U.S. population: Results from the 2002 HealthStyles Survey. Epilepsia. 2003;44(11):1449-54. doi: 10.1046/j.15281157.2003.17603.x. [PubMed: 14636355].

8. Alem A. Mental health services and epidemiology of mental health problems in Ethiopia. Ethiop Med J. 2001;39(2):153-65. [PubMed: 11501293].

9. Jacoby A. Stigma, epilepsy, and quality of life. Epilepsy Behav. 2002;3(6S2):10-20. doi: 10.1016/s1525-5050(02)00545-0. [PubMed: 12609301].

10. de Boer HM, Mula M, Sander JW. The global burden and stigma of epilepsy. Epilepsy Behav. 2008;12(4):540-6. doi: 10.1016/j.yebeh.2007.12.019. [PubMed: 18280210].

11. Guekht AB, Mitrokhina TV, Lebedeva AV, Dzugaeva FK, Milchakova LE, Lokshina $\mathrm{OB}$, et al. Factors influencing on quality of life in people with epilepsy. Seizure. 2007;16(2):128-33. doi: 10.1016/j.seizure.2006.10.011. [PubMed: 17157536].

12. Bautista RE, Wludyka P. Factors associated with employment in epilepsy patients. Epilepsy Behav. 2007;10(1):89-95. doi: 10.1016/j.yebeh.2006.10.006. [PubMed: 17118712]

13. Senol V, Soyuer F, Arman F, Ozturk A. Influence of fatigue, depression, and demographic, socioeconomic, and clinical variables on quality of life of patients with epilepsy. Epilepsy Behav. 2007;10(1):96-104. doi: 10.1016/j.yebeh.2006.08.006. [PubMed: 17097354].

14. Lua PL, Nor-Khaira-Wahida K, Zariah AA, Lee KF. Caregiving for epilepsy: Awareness, knowledge, attitude and health-related quality of life of family caregivers. Malays J Psychiatry. 2014;23(1):45-56.

15. Karimi N, Akbarian SA. Knowledge and attitude toward epilepsy of close family members of people with epilepsy in North of Iran. Adv Med. 2016;2016:8672853. doi: 10.1155/2016/8672853. [PubMed: 28116347]. [PubMed Central: PMC5220387].

16. Ghanean H, Jacobsson L, Nojomy M. Self-perception of stigma in persons with epilepsy in Tehran, Iran. Epilepsy Behav. 2013;28(2):163-7. doi: 10.1016/j.yebeh.2013.04.009. [PubMed: 23747500].

17. Neyaz HA, Aboauf HA, Alhejaili ME, Alrehaili MN. Knowledge and attitudes towards epilepsy in Saudi families. I Taibah Univ Med Sci. 2017;12(1):89-95. doi: 10.1016/j.jtumed.2016.06.007. [PubMed: 31435221]. [PubMed Central: PMC6695036].

18. Yeni K, Tulek Z, Bebek N, Dede O, Gurses C, Baykan B, et al. Attitudes towards epilepsy among a sample of Turkish patients with epilepsy. Epilepsy Behav. 2016;62:66-71. doi: 10.1016/j.yebeh.2016.06.022. [PubMed: 27450308].

19. Smithson WH, Hukins D, Buelow JM, Allgar V, Dickson J. Adherence to medicines and self-management of epilepsy: A community-based study. Epilepsy Behav. 2013;26(1):109-13. doi: 10.1016/j.yebeh.2012.10.021. [PubMed: 23246201].

20. Karimi N, Heidari M. Knowledge and attitudes toward epilepsy among school teachers in West of Iran. Iran J Neurol. 2015;14(3):130-5. [PubMed: 26622977]. [PubMed Central: PMC4662685].

21. Masoudnia E. Awareness, understanding and attitudes towards epilepsy among Iranian ethnic groups. Seizure. 2009;18(5):369-73. doi: 10.1016/j.seizure.2009.01.009. [PubMed: 19223209]

22. Ghanean H, Nojomi M, Jacobsson L. Public awareness and attitudes towards epilepsy in Tehran, Iran. Glob Health Action. 2013;6:21618 doi: 10.3402/gha.v6i0.21618. [PubMed: 24314322]. [PubMed Central: PMC3855600].

23. Kabir M, Iliyasu Z, Abubakar IS, Kabir ZS, Farinyaro AU. Knowledge, attitude and beliefs about epilepsy among adults in a northern Nigerian urban community. Ann Afr Med. 2005;4(3):107-12.

24. Long L, Reeves AL, Moore JL, Roach J, Pickering CT. An assessment of epilepsy patients' knowledge of their disorder. Epilepsia.2000;41(6):727-31. doi:10.1111/j.1528-1157.2000.tb00235.x. [PubMed: 10840406].

25. Coker MF, Bhargava S, Fitzgerald M, Doherty CP. What do people with epilepsy know about their condition? Evaluation of a subspecialty clinic population. Seizure. 2011;20(1):55-9. doi: 10.1016/j.seizure.2010.10.007. [PubMed: 21093304].

26. Choi-Kwon S, Kim EK, Youn SM, Choi JM, Lee SK, Chung CK. Common misconceptions in people with epilepsy. J Clin Neurol. 2006;2(3):18693. doi: 10.3988/jcn.2006.2.3.186. [PubMed: 20396505]. [PubMed Central: PMC2854963]

27. Samant JM, Lala VM, Ravindranath S, Desai AD. Social aspects of epilepsy. Neurol India. 1973;21:165-74.

28. Sunmonu TA, Afolabi OT, Komolafe MA, Ogunrin AO. Patients' knowledge about their disorder: Perspective of patients with epilepsy in a tertiary health facility in southwestern Nigeria. Epilepsy Behav. 2011;20(3):556-60. doi: 10.1016/j.yebeh.2010.12.030. [PubMed: 21277835].

29. Saengsuwan J, Laohasiriwong W, Boonyaleepan S, Sawanyawisuth K, Tiamkao S; Integrated Epilepsy Research Group. Knowledge, attitudes, and care techniques of caregivers of PWE in northeastern Thailand. Epilepsy Behav. 2013;27(1):257-63. doi: 10.1016/j.yebeh.2013.01.014. [PubMed: 23453636].

30. Tran DS, Odermatt P, Singphuoangphet S, Druet-Cabanac M, Preux PM, Strobel M, et al. Epilepsy in laos: Knowledge, attitudes, and practices in the community. Epilepsy Behav. 2007;10(4):565-70. doi 10.1016/j.yebeh.2007.02.018. [PubMed:17446140].

31. Yoo JK, Jung KY, Park KW, Lee DH, Lee SK, Lee IK, et al. Familiarity with, understanding of, and attitudes toward epilepsy among people with epilepsy and healthy controls in South Korea. Epilepsy Behav. 2009;16(2):260-7. doi: 10.1016/j.yebeh.2009.07.025. [PubMed: 19695960].

32. Saengsuwan J, Boonyaleepan S, Srijakkot J, Sawanyawisuth K, Tiamkao S; Integrated Epilepsy Research Group. Factors associated with knowledge and attitudes in persons with epilepsy. Epilepsy Behav. 2012;24(1):23-9. doi: 10.1016/j.yebeh.2012.03.006. [PubMed: 22503426].

33. Mameniskiene R, Sakalauskaite-Juodeikiene E, Budrys V. People with epilepsy lack knowledge about their disease. Epilepsy Behav. 2015;46:192-7. doi: 10.1016/j.yebeh.2015.03.002. [PubMed: 25847428].

34. Ak PD, Atakli D, Yuksel B, Guveli BT, Sari H. Stigmatization and social impacts of epilepsy in Turkey. Epilepsy Behav. 2015;50:50-4. doi: 10.1016/j.yebeh.2015.05.014. [PubMed: 26117273].

35. Aydemir N, Ozkara C, Unsal P, Canbeyli R. A comparative study of health related quality of life, psychological well-being, impact of illness and stigma in epilepsy and migraine. Seizure. 2011;20(9):679-85. doi: 10.1016/j.seizure.2011.06.017. [PubMed: 21764337].

36. Jacoby A, Gorry J, Gamble C, Baker GA. Public knowledge, private grief: A study of public attitudes to epilepsy in the United Kingdom and implications for stigma. Epilepsia. 2004;45(11):1405-15. doi: 10.1111/j.00139580.2004.02904.x. [PubMed: 15509242].

37. Spatt J, Bauer G, Baumgartner C, Feucht M, Graf M, Mamoli B, et al. Predictors for negative attitudes toward subjects with epilepsy: A representative survey in the general public in Austria. Epilepsia. 2005;46(5):736-42. doi: 10.1111/j.1528-1167.2005.52404.x. [PubMed: 15857441]. 